\title{
STRUKTUR KOMUNITAS PARASITOID YANG BERASOSIASI DENGAN PENGOROK DAUN TANAMAN BAWANG MERAH DI BALI
}

\author{
STRUCTURE OF THE ASSOCIATED PARASITOID COMMUNITY \\ WITH STONE LEEK LEAFMINER OF ONION IN BALI
}

\author{
Hamid $^{1 *}$ \\ ${ }^{1}$ Dosen STMIK STIKOM Indonesia \\ Jl. Tukad Pakerisan No. 97 Denpasar-Bali, Indonesia
}

\begin{abstract}
ABSTRAK
Keberadaan suatu jenis parasitoid pada suatu wilayah dengan ketinggian tertentu sangat ditentukan oleh beberapa faktor, diantaranya adalah faktor lingkungan fisik, ruang, sumber pakan, kehadiran parasitoid lain dan campur tangan manusia. Tujuan dari penelitian ini adalah untuk mengetahui struktur komunitas parasitoid yang berasosiasi dengan pengorok daun tanaman bawang merah meliputi indeks kelimpahan, indeks keragaman dan indeks dominansi di beberapa lokasi pertanaman bawang merah di Bali. Survei lapangan dilakukan secara reguler selama satu musim tanam. Pada lokasi pertanaman bawang merah dengan ketinggian $<500$ m dpl, meliputi daerah Kabupaten Badung dan Kabupaten Gianyar, pada areal pertanaman bawang merah di lokasi tersebut tidak ditemukan adanya parasitoid (indeks kelimpahan R1 = 0,00 ; indeks keragaman $\mathrm{H}^{\prime}=0,00$; indeks dominansi $\mathrm{D}=0,00$ ). Pada lokasi dengan ketinggian $\geq 500$ $1000 \mathrm{~m}$ dpl, meliputi beberapa lokasi di Kabupaten Tabanan, ditemukan 2 jenis parasitoid yaitu Hemiptarsenus varicornis sebanyak 3 ekor (indeks kelimpahan R1 = 0,6213; indeks keragaman $\mathrm{H}^{\prime}=$ 0,2544; indeks dominansi $\mathrm{D}=0,0100$ ) dan Opius sp. sebanyak 22 ekor (indeks kelimpahan $\mathrm{R} 1=6,5239$; indeks keragaman $\mathrm{H}^{\prime}=0,1125$; indeks dominansi $\mathrm{D}=0,7700$ ). Di lokasi dengan ketinggian $\geq 1000 \mathrm{~m}$ dpl, meliputi beberapa lokasi di Kabupaten Tabanan dan Kabupaten Bangli ditemukan juga 2 jenis parasitoid yaitu $\mathrm{H}$. varicornis 5 ekor (indeks kelimpahan $\mathrm{R} 1=1,2941$; indeks keragaman $\mathrm{H}^{\prime}=0,3380$; indeks dominansi $\mathrm{D}=0,0433$ ) dan Opius sp. sebanyak 17 ekor (indeks kelimpahan $\mathrm{R} 1=5,1763$; indeks keragaman $\mathrm{H}^{\prime}=0,2013$; indeks dominansi $\mathrm{D}=0,5887$ ).
\end{abstract}

Kata kunci: kelimpahan, keragaman, dominansi, parasitoid

\section{ABSTRACT}

The existence of a type of parasitoid in an area with a certain height is largely determined by several factors, including the physical environment, space, feed sources, the presence of other parasites and human intervention. The purpose of this study was to determine the community structure of parasitoid associated with stone leek leafminer including abundance index, diversity index and dominance index in several locations of onion planting in Bali. Field surveys are conducted regularly during one planting season. On the location of onion plantations with an altitude of $<500 \mathrm{~m}$ asl, covering the Badung Regency and Gianyar Regencies, on the onion planting area at that location no parasitoid was found (abundance index $R 1=0.00$; diversity index $H^{\prime}=0.00$; dominance index $D=0.00$ ). In locations with a height of $\geq 500-1000 \mathrm{~m}$ asl, covering several locations in Tabanan Regency, there were 2 types of parasitoid, Hemiptarsenus varicornis as many 3 adult (abundance index $R 1=0.6213$; diversity index $H^{\prime}=0.2544$; dominance index $D=0.0100$ ) and Opius sp. 22 adult (abundance index $R 1=6.5239$; diversity index $H^{\prime}=$ 0.1125; dominance index $D=0.7700$ ). In locations with an altitude of $\geq 1000 \mathrm{~m}$ asl, covering several locations in Tabanan Regency and Bangli Regency, there were also 2 types of parasitoid namely $H$. varicornis 5 adult (abundance index $R 1=1.2941$; diversity index $H^{\prime}=0.3380$; dominance index $D=$ 0.0433 ) and Opius sp. 17 adult (abundance index $R 1=5.1763$; diversity index $H^{\prime}=0.2013$; dominance index $D=0.5887$ ).

Keywords : abundance, diversity, dominance, parasitoid

\footnotetext{
*) Penulis Korespondensi.

E-mail: mhamidmsi@gmail.com

Telp: $+62-$
} 


\section{Pendahuluan}

Bawang merah (Allium cepa L.) merupakan komoditas unggulan yang mempunyai prospek untuk dikembangkan di Bali. Hasil bawang merah di tingkat petani masih rendah, dan salah satu faktor penyebab rendahnya produktivitas bawang merah di Bali adalah adanya serangan Liriomyza chinensis (Hamid et al., 2018). Hama ini merupakan serangga kosmopolitan, dan dalam beberapa tahun terakhir L. chinensis menjadi hama penting pada tanaman bawang merah di Bali (Hamid et al., 2018).

Parasitoid adalah organisme yang menghabiskan sebagian besar hidupnya dengan bergantung pada organisme inang tunggal untuk mengambil makanan dalam proses itu. Di Indonesia, pemanfaatan parasitoid sebagai agen hayati untuk mengendalikan $L$. chinensis masih terbatas. L. chinensis (Gambar 1) merupakan hama tanaman bawang merah, diketahui memiliki musuh alami, khusus di tempat aslinya. Setidaknya ada 23 spesies parasitoid telah digunakan dalam program pengendalian biologis terhadap Liriomyza sp. di Senegal, California, Hawaii, Barbados, Marianas, Tonga, Taiwan dan Guam (Petcharat, 2002; Cikman, 2012). Parasitoid dari famili Eulophidae, Braconidae dan Pteromalidae adalah parasitoid yang dominan menyerang stadia larva dan pupa dari lalat Agromyzidae (Cikman, 2012). Menurut Noyes (2004) bahwa terdapat lebih dari 300 spesies parasitoid Agromyzidae, dan lebih dari 80 spesies yang dikenal menyerang spesies Liriomyza sp. La Salle \& Parrella (1991) mendaftarkan 23 spesies parasitoid untuk Liriomyza sp. Di Indonesia tercatat 25 jenis parasitoid berasosiasi dengan Liriomyza sp. Pada kondisi alami larva Liriomyza sp. dapat terparasit oleh berbagi jenis parasitoid dan imagonya dimangsa oleh predator. Jenis parasitoid Liriomyza sp. berbeda untuk setiap tanaman dan daerah geografi atau penyebarannya (Rauf, 1999).

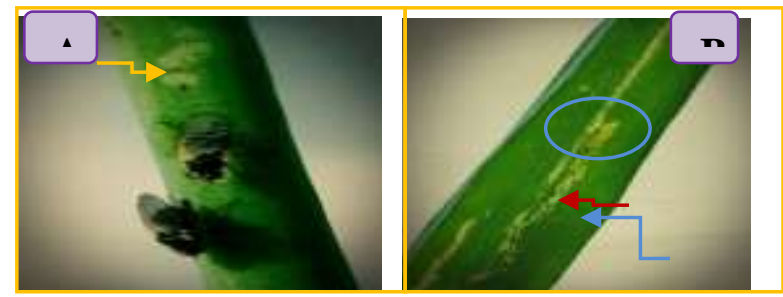

Gambar 1. Daun tanaman bawang merah yang terserang L. chinensis, (A) Bekas tusukan ovipositor imago betina $L$. chinensis (tanda panah warna kuning) dan (B) Bekas korokan larva L. chinensis (tanda panah warna merah)

\section{Metode Penelitian}

Penelitian ini dilakukan di daerah sentra penghasil bawang merah di Bali yang meliputi Kabupaten Badung, Tabanan, Bangli, Gianyar dan Karangasem (Gambar 2). Pengambilan sampel daun tanaman bawang merah yang terserang Liriomyza sp. dilakukan setiap minggu. Sampel terkoleksi dimasukkan ke dalam kantung plastik per lokasi, kemudian disimpan sementara di dalam cool box untuk dipindahkan ke dalam stoples penetasan di laboratorium. Imago Liriomyza sp. dan parasitoid yang muncul dimasukkan secara terpisah ke dalam botol koleksi berisi alkohol 90\% untuk kebutuhan identifikasi. Identifikasi Liriomyza sp. dilakukan dengan cara mencocokkan spesimen dengan ciri morfologi Liriomyza sp. yang dilakukan oleh Spencer dan Steyskal (1986), Malipatil et al. (2004) dan spesimen pembanding Hikmawati et al. (2013), sementara untuk parasitoid menggunakan acuan kunci dasar parasitoid di Asia oleh Fisher et al. (2005).

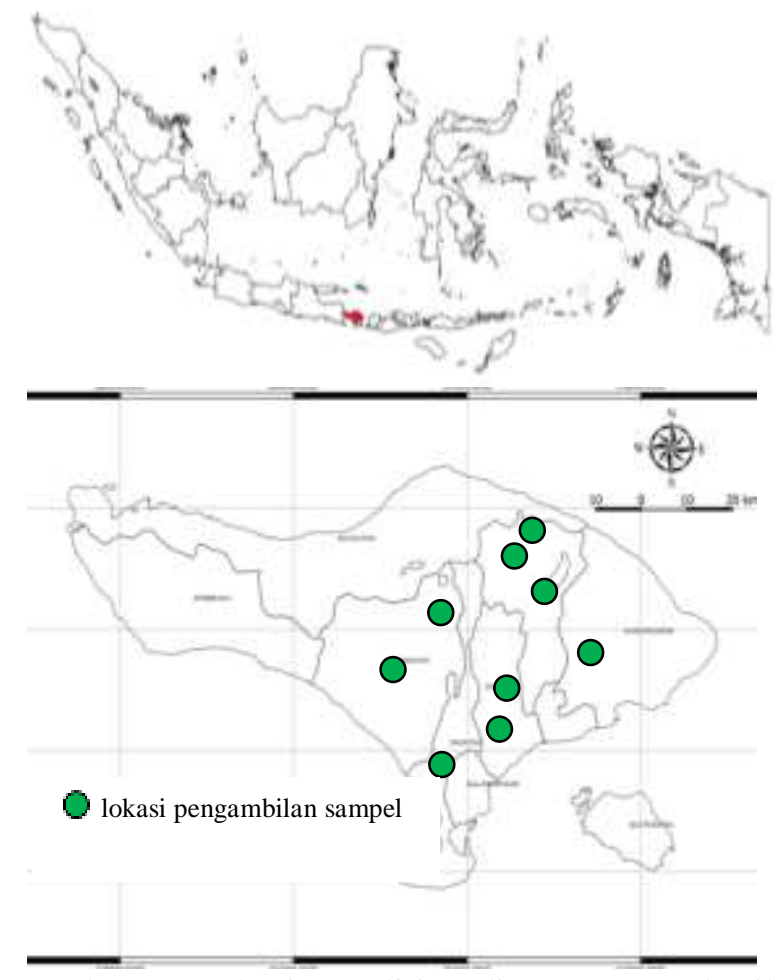

Gambar 2. Lokasi penelitian di sentra penghasil bawang merah di Bali

Untuk mengetahui struktur komunitas parasitoid yang berasosiasi dengan pengorok daun tanaman bawang merah meliputi indeks kelimpahan, indeks keragaman dan indeks dominansi pada setiap lokasi, dianalisis menggunakan rumus berikut : 


\section{Jurnal Agrotech 9 (2) 45-49}

1. Indeks kelimpahan menggunakan indeks Magalef (Magurran, 2005).

$$
\mathrm{R} 1=\frac{\mathrm{S}-1}{\ln \mathrm{N}}
$$

Keterangan:

R1 = Indeks kelimpahan

$\mathrm{S}=$ Jumlah jenis yang ditemukan

ln = Logaritme nature

$\mathrm{N}$ = Jumlah total individu

Nilai:

$\mathrm{R} 1<3,5=$ indeks kelimpahan rendah

$3,5<\mathrm{R} 1<5,0=$ indeks kelimpahan sedang

$\mathrm{R} 1>5,0=$ indeks kelimpahan tinggi

2. Indeks keragaman menggunakan suatu indeks yang dikembangkan oleh Shannon dan Wiener (H') melalui persamaan sebagai berikut :

$$
\begin{aligned}
& \mathrm{H}^{\prime}=-\sum \text { pi ln pi } \\
& \text { pi }=\sum \text { ni/N }
\end{aligned}
$$

Keterangan :

H' = Indeks keragaman Shannon-Wienner

pi $=$ Proporsi dari spesies ke-i pada komunitas

$\ln =$ Logaritme nature

ni $=$ Kelimpahan individu spesies ke-i

$\mathrm{N}=$ Jumlah total individu semua spesies

Nilai :

$\mathrm{H}^{\prime}<1,0=$ indeks keragaman rendah

$1<\mathrm{H}^{\prime}<3=$ indeks keragaman sedang

$\mathrm{H}^{\prime}>3,0=$ indeks keragaman tinggi

3. Indeks dominansi dihitung menggunakan indeks Menheinick (Magurran, 2005).

$$
\mathrm{D}=\sum\left(\frac{\mathrm{ni}(\mathrm{ni}-1)}{\mathrm{N}(\mathrm{N}-1)}\right)
$$

Keterangan :

$\mathrm{D}=$ Indeks dominansi

$\mathrm{N}$ = Jumlah total indidividu

ni $=$ Jumlah individu jenis ke- $\mathrm{i}$

Nilai :

$0,00<\mathrm{D}<0,30=$ indeks dominansi rendah

$0,30<\mathrm{D}<0,60=$ indeks dominansi sedang

$0,60<\mathrm{D}<1,00=$ indeks dominansi tinggi
e-ISSN : 2621-7236

p-ISSN : 1858-134X

\section{Hasil dan Pembahasan}

Parasitoid memegang peranan yang sangat penting pada agroekosistem karena secara alami dapat mengendalikan keberadaan hama. Kajian terhadap indeks kelimpahan, indeks keragaman dan indeks dominansi parasitoid dari beberapa lokasi pertanaman bawang merah di Bali, adalah untuk mendapatkan gambaran tentang keberadaan parasitoid yang berasosiasi dengan serangga inang $L$. chinensis pada tanaman bawang merah. Keberadaan suatu jenis parasitoid pada suatu wilayah dengan ketinggian tertentu sangat ditentukan oleh beberapa faktor, diantaranya adalah faktor lingkungan fisik, ruang, sumber pakan, kehadiran parasitoid lain dan campur tangan manusia.

Pada lokasi pertanaman bawang merah dengan ketinggian $<500 \mathrm{~m}$ dpl, meliputi daerah Kabupaten Badung dan Kabupaten Gianyar, pada areal pertanaman bawang merah di lokasi tersebut, tidak ditemukan adanya serangan $L$. chinensis, dan keadaan ini juga menyebabkan tidak ditemukannya parasitoid di lokasi tersebut. Fenomena ini mengindikasikan belum terjadi invasi $L$. chinensis pada pertanaman bawang merah yang ditanam pada lokasi dataran rendah ( $<500 \mathrm{~m}$ dpl). Pada lokasi dengan ketinggian $\geq 500-1000 \mathrm{~m}$ dpl, meliputi beberapa lokasi di Kabupaten Tabanan, didapat 25 ekor imago parasitoid yang muncul dari hasil pemeliharaan daun tanaman bawang merah yang terserang $L$. chinensis. Jenis parasitoid yang ditemukan dengan ketinggian $\geq 500-1000 \mathrm{~m}$ dpl yaitu dari Famili Eulophidae (Hemiptarsenus varicornis) dan Famili Braconidae (Opius sp.) (Gambar 3). Dari kedua jenis parasitoid tersebut yang paling banyak populasinya adalah Opius sp. yaitu 22 ekor atau $88 \%$ dari total parasitoid yang muncul (Tabel 1). Begitu juga pada lokasi dengan ketinggian $\geq 1000 \mathrm{~m}$ dpl, meliputi beberapa lokasi di Kabupaten Tabanan dan Kabupaten Bangli, didapat 22 ekor imago parasitoid yang muncul dari hasil pemeliharaan daun tanaman bawang merah yang terserang L. chinensis. Jenis parasitoid yang ditemukan pada ketinggian $\geq 1000 \mathrm{~m}$ yaitu juga dari Famili Eulophidae $(H$. varicornis) dan Famili Braconidae (Opius sp.). Dari kedua jenis parasitoid tersebut yang lebih banyak populasinya adalah Opius sp. yaitu 17 ekor atau $77 \%$ dari total parasitoid yang muncul (Tabel 1). 
Tabel 1. Jenis parasitoid yang ditemukan di pertanaman bawang merah pada beberapa lokasi ketinggian tempat yang berbeda

\begin{tabular}{|c|c|c|c|c|c|c|}
\hline Lokasi & Famili & Spesies & $\begin{array}{c}\text { Jumlah } \\
\text { (ekor) }\end{array}$ & $\begin{array}{c}\text { Indeks } \\
\text { Kelimpahan }\end{array}$ & $\begin{array}{c}\text { Indeks } \\
\text { Keragaman }\end{array}$ & $\begin{array}{c}\text { Indeks } \\
\text { Dominansi }\end{array}$ \\
\hline Dataran Rendah & Eulophidae & H. varicornis & 0 & 0 & 0 & 0 \\
\hline$(<500 \mathrm{~m} \mathrm{dpl})$ & Braconidae & Opius sp. & 0 & 0 & 0 & 0 \\
\hline Dataran Sedang & Eulophidae & H. varicornis & 3 & 0,6213 & 0,2544 & 0,0100 \\
\hline$(\geq 500-1000 \mathrm{~m} \mathrm{dpl})$ & Braconidae & Opius sp. & 22 & 6,5239 & 0,1125 & 0,7700 \\
\hline Dataran Tinggi & Eulophidae & H. varicornis & 5 & 1,2941 & 0,3380 & 0,0433 \\
\hline$(\geq 1000 \mathrm{~m} \mathrm{dpl})$ & Braconidae & Opius sp. & 17 & 5,1763 & 0,2013 & 0,5887 \\
\hline
\end{tabular}

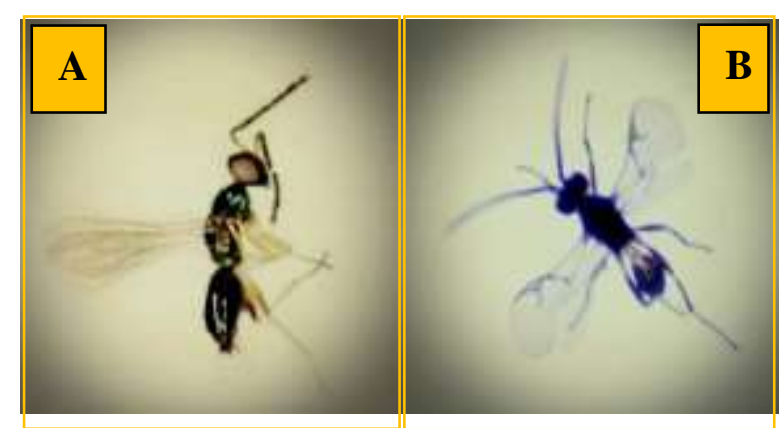

Gambar 3. Jenis parasitoid yang ditemukan di pertanaman bawang merah (A) $H$. varicornis (B) Opius sp.

Indeks kelimpahan, indeks keragaman dan indeks dominansi parasitoid yang didapat dari beberapa lokasi pertanaman bawang merah di Bali tersaji pada Tabel 1. Pada lokasi pertanaman bawang merah dengan ketinggian $<500 \mathrm{~m}$ dpl, meliputi daerah Kabupaten Badung dan Kabupaten Gianyar, pada areal pertanaman bawang merah di lokasi tersebut tidak ditemukan adanya parasitoid (indeks kelimpahan $\mathrm{R} 1=0,00$; indeks keragaman $\mathrm{H}^{\prime}=0,00$; indeks dominansi $\mathrm{D}$ $=0,00)$. Pada lokasi dengan ketinggian $\geq 500$ $1000 \mathrm{~m}$ dpl, meliputi beberapa lokasi di Kabupaten Tabanan, ditemukan 2 jenis parasitoid yaitu $H$. varicornis sebanyak 3 ekor (indeks kelimpahan $\mathrm{R} 1=0,6213$; indeks keragaman $\mathrm{H}^{\prime}=$ 0,2544 ; indeks dominansi $\mathrm{D}=0,0100$ ) dan Opius sp. sebanyak 22 ekor (indeks kelimpahan $\mathrm{R} 1=$ 6,5239; indeks keragaman $\mathrm{H}^{\prime}=0,1125$; indeks dominansi $\mathrm{D}=0,7700$ ). Di lokasi dengan ketinggian $\geq 1000 \mathrm{~m}$ dpl, meliputi beberapa lokasi di Kabupaten Tabanan dan Kabupaten Bangli ditemukan juga 2 jenis parasitoid yaitu $H$. varicornis 5 ekor (indeks kelimpahan R1 = 1,2941; indeks keragaman $\mathrm{H}^{\prime}=0,3380$; indeks dominansi $\mathrm{D}=0,0433$ ) dan Opius sp. sebanyak 17 ekor (indeks kelimpahan R1 = 5,1763; indeks keragaman $\mathrm{H}^{\prime}=0,2013$; indeks dominansi $\mathrm{D}=$ 0,5887). Aquilino et al. (2005) menyatakan bahwa lingkungan yang stabil memiliki nilai indeks kelimpahan (R1) dan keragaman (H') tinggi serta dominansi (D) rendah. Populasi Opius sp. di lapangan dengan ketinggian $\geq 500$ $1000 \mathrm{~m}$ dpl dan ketinggian $\geq 1000 \mathrm{~m}$ dpl menunjukkan bahwa parasitoid tersebut memiliki potensi yang tinggi sebagai musuh alami untuk mengendalikan hama pengorok daun. Parasitoid ini telah dilaporkan merupakan musuh alami yang efektif untuk mengendalikan pengorok daun pada berbagai jenis tanaman inang (Rauf et al., 2000; Purnomo, 2009; Hidrayani et al., 2005; Wahyuni et al., 2017). Rendahnya parasitoid yang ditemukan di lapang pada penelitian ini, kemungkinan dikarenakan aplikasi insektisida sintetik oleh petani yang berlebihan, yang aplikasinya dapat mencapai 2-3 kali perminggu. Pernyataan ini juga didukung dari hasil penelitian Prijono et al. (2004) bahwa aplikasi insektisida yang berlebihan menyebabkan kematian pada imago parasitoid.

\section{Kesimpulan}

1. Hanya dua parasitoid yang ditemukan berasosiasi dengan L. chinensis pada tanaman bawang merah dari beberapa lokasi pertanaman bawang merah di Bali. Parasitoid tersebut adalah $H$. varicornis (Hymenoptera : Eulophidae) dan Opius sp. (Hymenoptera : Braconidae).

2. Indeks keragaman parasitoid yang didapat dari beberapa lokasi pertanaman bawang merah di Bali sangat rendah.

\section{Daftar Pustaka}

Aquilino, K. M., B. J. Cardinale, and A. R. Ives . 2005. Reciprocal Effects of Host Plant and Natural Enemy Diversity on Herbivore Suppression : an Empirical Study of a Model Tritrophic System. Oikos. $108:$ 275-282.

Cikman, E. 2012. Parasitoids of The Leafminers (Diptera : Agromyzidae) from Elazig Province, Turkey. Afr. J. Agric. Res. 7 : 1937-1943. 
Jurnal Agrotech 9 (2) 45-49

Fisher, N., R.Ubaidillah, P. Reina, and J. La Salle . 2005. Liriomyza Parasitoids in Southeast Asia. World Wibe Web Electronic Publication.

Hamid., I W. Supartha, I W. Susila, and I P. Sudiarta . 2018. Flight Behavior, Development of Population and Attack of Stone Leek Leafminer Liriomyza chinensis Kato (Diptera: Agromyzidae) towards Five Varieties of Onion (Allium Cepa L.). International Journal of Life Sciences. 2 (2) : 51-63.

Hamid., I W. Supartha, I W. Susila, and I P. Sudiarta . 2018. Morphological and Molecular Characteristics of Liriomyza sp. (Diptera : Agromyzidae) on Onion Plants (Allium cepa L.) in Bali. Asian Journal of Agriculture and Biology. 6 (4) : 524-529.

Hidrayani, P., A. Rauf, P. M. Ridland, and A. A .Hoffmann . 2005. Pesticide Applications on Java Potato Fields are Ineffective in Controlling Leafminers, and Have Antagonistic Effects on Natural Enemies of Leafminers. Int. J. Pest Mgmt. 51: 181-187.

Hikmawati, A., Hasrianty dan Shahabuddin. 2013. Kajian Jenis Pengorok Daun (Liriomyza sp.) (Diptera : Agromyzidae) pada Berbagai Tanaman Inang di Lembah Palu. e-J. Agrotekbis. 1 : 204210.

La Salle, J. and M. P. Parrella. 1991. The Chalcidoid Parasites (Hymenoptera : Chalcidoidea) of Economically Important Liriomyza species (Diptera : Agromyzidae) in North America. Proc. Entomol. Soc. Wash. 93 : 571-591.

Magurran, A. E. 2005. Measuring Biological Diversity. Blackwell Publishing. Oxford, UK

Malipatil, M.B., P. M. Ridland, A. Rauf, J. Watung, and D. Kandowangko . 2004. New Records of Liriomyza Mik (Agromyzidae : Diptera) Leafminers from Indonesia. Formosan Entomol. 24 : 287-292.
e-ISSN : 2621-7236

p-ISSN : 1858-134X

Noyes, J. S. 2004. Metaphycus and Related Genera, Parasitoids of Scale Insects (Coccoidea) and Whiteflies (Aleyrodidae). Memoirs of The American Entomological Institute. $73: 3-4$.

Petcharat, J. 2002. Larval Parasitoids of Agromyzid Leafminer Genus in The Southern Thailand : Species and Their Host Plants. Songklanakarin Journal of Scientific Technology. 24 : 467-472.

Prijono, D., M. Robinson, A. Rauf, T. Bjorksten, and A. A. Hoffmann . 2004. Toxicity of Chemicals Commontly Used in Indonesia Vegetable Crops to Liriomyza huidobrensis Populations and The Indonesian Parasitoids Hemiptarsenus varicornis, Opius sp., and Gronotoma micromorpha, as well as The Australian Parasitoids Hemiptarsenus varicornis and Dyglyphus isaca. J. Econ. Entomology. 97 : 1191-1197.

Purnomo, H. 2009. Pengantar Pengendalian Hayati. Yogyakarta : CV Andi Offset.

Rauf, A. 1999. Persepsi dan Tindakan Petani Kentang Terhadap Lalat Pengorok Daun, Liriomyza huidobrensis (Blanchard) (Diptera: Agromyzidae). Buletin Hama dan Penyakit Tumbuhan. $11: 1-13$.

Rauf, A., B. M. Shepard, and M. W. Johnson . 2000. Leafminers in Vegetables, Ornamental Plants and Weeds in Indonesia: Surveys of Host Crops, Species Composition and Parasitoids. Intern. J. Pest Manage. 46 : 257-266.

Spencer, K. A. and B. C. Steyskal. 1986. Manual of The Agromyzidae (Diptera) of United States. USDA Agric. Handb. No.638. p. 478.

Wahyuni, S., I W. Supartha, R. Ubaidillah, and I N. Wijaya . 2017. Parasitoid Community Structure of Leaf Miner Liriomyza spp. (Diptera : Agromyzidae) and The Rate of Parasitization on Vegetable Crops in Lesser Sunda Island, Indonesia. BIODIVERSITAS. 18 : 593-600. 